\title{
The effect of disease activity on body composition and resting energy expenditure in patients with rheumatoid arthritis
}

This article was published in the following Dove Press journal:

Journal of Inflammation Research

20 May $201 \mathrm{I}$

Number of times this article has been viewed

K Binymin ${ }^{1,3}$

AL Herrick'

GL Carlson ${ }^{2}$

SJ Hopkins ${ }^{2}$

'University of Manchester, Rheumatic Diseases Centre, ${ }^{2}$ Infection Injury and Inflammation Group, and Brain Injury Research Group, Manchester Academic Health Science Centre and University of Manchester Faculty of Medical and Human Sciences, Salford Royal Hospitals NHS Trust, Salford, UK; ${ }^{3}$ Southport District General Hospital, Southport, UK
Correspondence: K Binymin University of Liverpool, Rheumatology Unit, Liverpool L69 3BX, UK Tel $+44(0)$ I70454747I

Fax +44 (0) 17044579

Email kbinymin@nhs.net
Introduction: Cachexia is associated with rheumatoid arthritis (RA), but whether it is attributable primarily to reduced dietary intake or increased metabolism is unclear, as is the association with inflammation. To examine whether rheumatoid cachexia is related to increased energy expenditure, reduced food intake, or an inflammatory cytokine response we undertook a prospective, longitudinal study of patients with RA, during periods of relative relapse and remission of inflammation.

Methods: Sixteen patients admitted to hospital with a flare of RA were assessed clinically to determine disease activity and were re-examined 6 weeks later. Their fat-free mass (FFM), dietary intake, resting energy expenditure (REE), and plasma concentrations of interleukin-6 (IL-6) were also measured. Data were compared with those from 16 healthy, age- and sex-matched controls.

Results: At baseline the body weight, body mass index, and FFM of patients with RA were significantly lower than those of controls. Disease activity scores of patients $(6.39 \pm 0.8)$ were reduced when the patients were re-examined 6 weeks later $(5.23 \pm 1.26)$ and FFM was no longer statistically different from that of controls (visit $1=25.8 \pm 10.1$ and visit $2=26.8 \pm 9.5$ versus controls $=32.3 \pm 10.9$ ). There were no differences in food intake between patients and controls or between patients studied at the 2 time points, but REE was greater in patients after correcting for FMM (visit $1=62.2 \pm 24.7$, visit $2=59.7 \pm 26.3$ versus controls $=46.0 \pm 13.7$ ). Plasma IL-6 concentrations were significantly higher in patients than controls. Although IL-6 was not significantly correlated with REE, lower REE measurements were not observed when the plasma IL-6 concentration increased.

Conclusion: Reduced FFM in patients with RA is not attributable to reduced food intake. Energy expenditure is greater in patients when corrected for FFM, particularly in patients with acute flares of disease activity. Although clearly not the only factor involved, increased production of IL-6 may contribute to increasing REE.

Keywords: rheumatoid arthritis, cachexia, free-fat mass, fat mass, resting energy expenditure, interleukin-6

\section{Introduction}

Weight loss in individuals with rheumatoid arthritis (RA) has been recognized since early observations of the disease. ${ }^{1}$ More recent studies have indicated that a moderate degree of cachexia may be present in a substantial number of patients with RA. ${ }^{2,3}$ As with the cachexia associated with cancer or infection, underlying mechanisms are uncertain. Data from studies of RA have suggested that tumor necrosis factor alpha (TNF- $\alpha$ ) or interleukin-1 (IL-1) might be important in the cachexia associated with RA. ${ }^{4}$ These cytokines are, however, rarely found in plasma, although increased plasma IL-6 is 
commonly found in patients with arthritis and concentrations are related to inflammatory activity. ${ }^{5-7}$ IL- 6 is induced by IL- 1 and TNF- $\alpha^{8}$ and has important systemic functions in inflammation. ${ }^{8}$ It has been implicated in animal models of cachexia $^{9-11}$ and in patients with cancer ${ }^{12,13}$ although its link to cachexia in RA is unclear.

RA is characterized by a remitting and relapsing clinical course. It therefore seemed reasonable to hypothesize that the mechanism(s) responsible for cachexia would be activated most clearly during periods of increased disease activity. Previous studies have been of a cross-sectional nature and have not been able to directly address this possibility. ${ }^{2-4}$ We therefore set out to examine whether cachexia in RA was associated with increased energy expenditure and/or reduced food intake, or with plasma IL-6 concentrations, in a prospective, longitudinal study of patients with RA, during periods of relative relapse and remission.

\section{Materials and methods}

Sixteen adult patients with active joint disease and RA, as defined by the revised criteria of the American Rheumatology Association ${ }^{14}$ were admitted under the care of the rheumatological rehabilitation services of Ladywell Hospital, Salford, for treatment of an increase in disease activity. All patients were Caucasian and were age- and sex-matched ( 4 male: 12 female mean age $52 \pm 14.9$ years) with 16 apparently healthy control subjects (4 male:12 female, mean age $51 \pm 11.9$ years). Each patient was studied within 48 hours of hospital admission and then again 6 weeks later. Eight patients were taking oral steroids during the study time. Patients with concurrent or chronic infection, other inflammatory conditions, conditions primarily associated with weight change (malignancy, thyroid disease, diabetes mellitus, congestive cardiac failure, pregnancy), or taking medication known to affect metabolic rate (thyroxine, $\beta$-blockers or $\beta$-agonists) were excluded from the study.

\section{Clinical assessment}

All patients were assessed clinically on first and second visits using the following measures: 1) Disease activity was measured using the 28-joint-based disease activity score (DAS); ${ }^{15}$ 2) morning stiffness in hours; 3) physician's global assessment of disease activity, graded on a scale of $1-5$, where $1=$ asymptomatic and $5=$ very severe ${ }^{16}$ 4) patient assessment of joint pain and disease activity using a visual analog scale; ${ }^{16}$ 5) the modified health assessment questionnaire (mHAQ); ${ }^{17}$
6) the visual analog scale for pain. ${ }^{18} \mathrm{~A}$ single assessor conducted all clinical examination and scoring.

\section{Anthropometric measurement}

Height was measured to the nearest $5 \mathrm{~mm}$ using a wallmounted stadiometer (Seca, Birmingham, UK), with the subject standing erect without shoes. Weight was measured to the nearest $0.025 \mathrm{~kg}$, using a calibrated Avery beam balance (Avery Ltd. Birmingham, UK). Skinfold thickness was measured with Harpenden calipers (Holtain Ltd, Crymych, UK), at 4 sites (biceps, triceps, suprailiac, and subscapular) and percentage body fat was calculated using the technique of Durnin and Womersley. ${ }^{19}$ Fat mass (FM) and fat-free body mass (FFM) were calculated using the Durnin and Womersley standard tables. Body mass index (BMI) was calculated using the formula: weight/(height $)^{2}$. One individual, trained in the techniques, performed all anthropometric measurements.

\section{Energy metabolism}

Resting energy expenditure (REE) was measured by continuous open circuit indirect calorimetry, using a Deltatrac metabolic monitor (Datex Ltd, Helsinki, Finland). ${ }^{20}$ The system was validated with quantitative alcohol combustion prior to use and returned at least $98 \%$ of predicted values. On the morning of each assessment the system was calibrated with the manufacturer's recommended gases. All measurements were performed between 08:00 and 08:30 hours, after a 10- to 12-hour fast. Measurements were made after a 30-minute period of rest, with the subject lightly clothed and awake, breathing room air quietly in a supine position. Oxygen consumption $\left(\mathrm{VO}_{2}\right)$ and carbon dioxide production $\left(\mathrm{VCO}_{2}\right)$ were measured for 30 minutes and the mean values used in subsequent calculations. $\mathrm{VO}_{2}$ and $\mathrm{VCO}_{2}$ were used to calculate REE, employing the formula of Weir. ${ }^{20}$

\section{Dietary intake}

Each patient's dietary intake was calculated by evaluating 7 , nonconsecutive, self-administered, 24-hour dietary histories over the 6-week period between the 2 assessment visits for patients and over the same period for the controls. Dietary analysis was carried out by entering types and quantities of food consumed into 'Microdiet' software (Salford University, Salford, UK), using McCance and Widdowson's composition of food tables. ${ }^{22}$ Energy content was calculated for patients and controls. Protein intake per kg body weight was calculated using 24-hour urinary nitrogen measurements. ${ }^{23}$ 
Table I Clinical characteristics of study subjects with RA at visits I and 2

\begin{tabular}{llll}
\hline Characteristics & Visit I & Visit 2 & P value \\
\hline Number & 16 & 16 & \\
Duration of RA (y) & $9.4 \pm 7.6$ & - & \\
No. tender joints & $13.5( \pm 4.2)$ & $5.8( \pm 5.1)$ & $<0.0 \mathrm{I}$ \\
No. swollen joints & $13.6 \pm 4.5$ & $9.1 \pm 4.0$ & 0.02 \\
Morning stiffness (h) & $2.1 \pm 1.2$ & $1.2 \pm 1.0$ & $<0.0 \mathrm{I}$ \\
Patient assessment of disease & $7.0 \pm 1.5$ & $4.5 \pm 4.6$ & $<0.0 \mathrm{I}$ \\
activity (VAS; 0-10 cm) & & & \\
$\begin{array}{l}\text { DAS 28 score } \\
\text { Physician assessment of disease }\end{array}$ & $2.8 \pm 0.5$ & $2.3 \pm 1.0$ & 0.03 \\
activity (score [I-5]) & & & \\
mHAQ (0-3) & $1.3 \pm 0.5$ & $0.9 \pm 0.6$ & 0.02 \\
VAS pain (cm [0-I0]) & $7.1 \pm 1.8$ & $5.1 \pm 3$ & $<0.0 \mathrm{I}$ \\
Mean prednisolone dose $(\mathrm{mg})^{\mathrm{a}}$ & $7.8 \pm 3.4$ & $8.1 \pm 3.4$ & 0.56 \\
\hline
\end{tabular}

Notes: Values represent means \pm SD (standard deviation); ${ }^{8} 8 / 16$ patients used steroids; Values are mean values of the 8 patients for visits I and 2; $P$ was set at significant at 0.05 .

Abbreviations: DAS, disease activity score; mHAQ, modified Health Assessment Questionnaire; RA, rheumatoid arthritis; VAS, visual analog score.

\section{Laboratory measurements}

Urinary nitrogen content was measured by an automated micro-Kjeldahl technique (Foss Electric, Copenhagen). ${ }^{24}$ Plasma IL-6 concentrations and C-reactive protein (CRP) were measured by enzyme-linked immunosorbant assays, as described by Holt et al. ${ }^{25}$ The erythrocyte sedimentation rate (ESR) was determined by the Westergren method.

\section{Statistical analysis}

All reported values are means $\pm \mathrm{SD}$, or median with range, and comparisons between groups (cases and controls) were analyzed using a $t$ test or a Mann-Whitney test, depending on their distribution. For within-group analysis with normally distributed values, a paired $t$ test was used, and for the nonparametric data a Wilcoxon rank test was applied. A bivariate correlation analysis (Spearman) was used to study the association between anthropometric variables and IL-6. A $P$ value $<0.05$ was chosen as indicative of statistical significance. Comparison of REE and food intake between patients and controls, and the relationship between IL- 6 and
(REE) were primary outcome measures. All other analyses were secondary and exploratory.

\section{Results \\ Disease activity}

Disease activity in patients was significantly reduced at the second visit for morning stiffness, DAS 28 score, physician's assessment of disease activity, and mHAQ (Table 1). Mean ESR, CRP, and IL-6 were significantly greater in patients than controls at both visits (Table 2).

\section{Anthropometry and energy balance}

Differences in anthropometric measurements between controls and patients at visit 1 and visit 2 are shown in (Table 3). Patients with RA had a significantly lower body weight and BMI than controls at both visits and body weight of patients increased significantly at visit 2 . The difference between patients and controls was largely attributable to a lower FFM, although this did increase by an average of $1 \mathrm{~kg}$ at visit 2 and was no longer significantly different from controls. Absolute values for REE in patients and controls were similar. However, when REE was corrected for FFM, patients had a significantly higher REE than controls at both visits. Energy and protein intake of patients was calculated to be at least as great as for controls (Table 4). Since half the patients recruited were taking prednisolone, we examined whether this might have an influence on the anthropometric or energy expenditure data, but there was no evidence for a significant effect on any variable (data not shown). Examining the correlation between IL-6 and anthropometric variables, BMI, FM, FFM, or REE revealed no statistically significant relationships, although the correlation for REE was $0.3(95 \%$ $\mathrm{CI}=-0.05270$ to $0.6195 ; P=0.08)$ and lower REE values were not apparent at higher IL-6 concentrations (Figure 1).

\section{Discussion}

In contrast to simple starvation, where more than threequarters of the initial weight loss arises from reduction of

Table 2 Laboratory measurements in patients with RA at visits I and 2 compared with matched controls

\begin{tabular}{|c|c|c|c|c|c|c|}
\hline Characteristic & Patient visit I & Patient visit 2 & Controls & $P_{1}$ value visit I & $P_{2}$ value visit 2 & $\begin{array}{l}P_{3} \text { value visit I } \\
\text { vs visit } 2\end{array}$ \\
\hline $\mathrm{ESR}(\mathrm{mm} / \mathrm{h})$ & $46(10-87)$ & $46(5-95)$ & $8(3-16)$ & $<0.001$ & 0.002 & 0.49 \\
\hline CRP (mg/L) & $52(7-108)$ & $57(3-224)$ & $6(4-9)$ & $<0.001$ & 0.001 & 0.39 \\
\hline IL-6 (pg/mL) & $23(2.7-82.5)$ & $17(2.7-56.6)$ & $4(1.9-7.2)$ & 0.002 & 0.003 & 0.21 \\
\hline
\end{tabular}

Notes: $P_{1}\left(P\right.$ value) patients in visit I visit compared with controls (Mann-Whitney); $P_{2}\left(P\right.$ value) patients in visit 2 compared with controls $\left(\right.$ Mann-Whitney); $P_{3}(P$ value) patients in visit I compared with patients in visit 2 (Wilcoxon); All values are median (range).

Abbreviations: ESR, erythrocyte sedimentation rate; CRP, C reactive protein; IL-6, interleukin-6. 
Table 3 Anthropometric and metabolic measurements in patients with RA compared with matched controls

\begin{tabular}{lcccccc}
\hline Characteristic & Patient visit I & Patient visit 2 & Controls & $\boldsymbol{P}_{1}$ value visit I* & $\boldsymbol{P}_{2}$ value visit 2* & $\begin{array}{c}\boldsymbol{P}_{3} \text { value visit I } \\
\text { vs visit 2* }\end{array}$ \\
\hline Weight $(\mathrm{kg})$ & $58.7 \pm 7.1$ & $59.4 \pm 7.2$ & $68.0 \pm 13.7$ & 0.01 & 0.01 & $<0.01$ \\
Height $(\mathrm{cm})$ & $160.7 \pm 7.1$ & $160.7 \pm 7.1$ & $162.5 \pm 7.1$ & 0.24 & 0.24 & 0.42 \\
$\mathrm{BMI}\left(\mathrm{kg} / \mathrm{Ht}\left[\mathrm{m}^{2}\right]\right)$ & $22.7 \pm 3.1$ & $22.9 \pm 3.1$ & $25.5 \pm 3.8$ & 0.01 & 0.02 & $0.5 \mathrm{I}$ \\
FM $(\mathrm{kg})$ & $33.6 \pm 8.8$ & $32.0 \pm 9.3$ & $36.6 \pm 6.8$ & 0.14 & 0.06 & 0.04 \\
FFM $(\mathrm{kg})$ & $25.8 \pm 10.1$ & $26.8 \pm 9.5$ & $32.3 \pm 10.9$ & 0.04 & 0.07 & $0.1 \mathrm{I}$ \\
REE $(\mathrm{kcal} /$ day) & $1407 \pm 212$ & $1378 \pm 191$ & $1388 \pm 200$ & 0.39 & 0.43 & 0.13 \\
REE/FFM (kcal/kg[FF]/day) & $62.2 \pm 24.7$ & $59.7 \pm 26.3$ & $46.0 \pm 13.7$ & 0.02 & 0.05 & 0.22 \\
\hline
\end{tabular}

Notes: $P_{1}(P$ value $)$ patients in visit I compared with controls; $P_{2}(P$ value $)$ patients in visit 2 compared with controls; $P_{3}(P$ value $)$ patients in visit $I$ compared with patients in visit 2; Values represent means \pm SD ( $t$ test).

Abbreviations: BMI, body mass index; FM, fat mass; FFM, fat-free mass; REE, resting energy expenditure.

adipose tissue and only a small amount from loss of skeletal muscle, ${ }^{26}$ cachexia is characterized by depletion of lean body mass, with profound loss of skeletal muscle. ${ }^{27}$ This was apparent in the present study, where FFM was significantly lower in patients admitted to the study than healthy age- and sex-matched control subjects. All patients studied had very active disease, as reflected by their high DAS. At the visit 2 , when disease activity had reduced, there was a significant increase in weight, although this was accompanied by a fall in FM. The absence of a dramatic change in FFM or BMI between visits may reflect the fact that, although REE might change rapidly in relation to inflammatory disease activity, FFM would be expected to change relatively slowly, as a cumulative result of periods of changed disease activity and energy expenditure.

FFM is a major determinant of metabolic rate in nondieting subjects. ${ }^{28}$ However, lower FFM in patients, relative to controls, was not matched by significantly reduced REE. When REE was corrected for FFM, the energy expenditure per $\mathrm{kg}$ of FFM was significantly greater in patients than controls. This was most evident in patients at visit 1 but at visit 2 was not decreased significantly, compared with control values.

Since the energy intake of patients in the present study was not reduced, relative to controls, our findings are in

Table 4 Dietary energy intake in patients with rheumatoid arthritis compared with controls

\begin{tabular}{lccc}
\hline & Patients & Controls & P value \\
\hline $\begin{array}{l}\text { Energy intake } \\
\text { (kcal/day) }\end{array}$ & $178 \mathrm{I} \pm 70 \mathrm{I}$ & $\mathrm{I} 723 \pm 5 \mathrm{I7}$ & 0.47 \\
$\begin{array}{l}\text { Energy intake/weight } \\
\text { (kcal/kg/day) }\end{array}$ & $30.3 \pm 12.0$ & $24.7 \pm 7.4$ & 0.12 \\
$\begin{array}{l}\text { Protein intake } \\
\text { (g/day) }\end{array}$ & $96.0 \pm 23.0$ & $70.0 \pm 14.0$ & 0.47 \\
$\begin{array}{l}\text { Protein intake } \\
\text { g/kg/day }\end{array}$ & $\mathrm{I} .6 \pm 0.3$ & $1.0 \pm 0.2$ & 0.32 \\
\hline
\end{tabular}

Note: Values represent means \pm SD $(t$ test). accord with results of a study of patients following trauma or sepsis, in which dietary intake was not considered to play an important role in causing cachexia. ${ }^{29}$ Our study findings are consistent with the view that increased disease and metabolic activity lead to accelerated FFM depletion in patients with RA. Accordingly, it seems reasonable to expect that the extent of cachexia in RA patients would be determined by a combination of intensity, duration, and frequency of active inflammatory disease. This analysis sheds some light on the possible sequence of events that culminate in the development of cachexia and may help explain the high prevalence of cachexia in RA. These results support and extend findings of a cross-sectional study of RA patients, which found that REE was higher in RA patients than controls. ${ }^{4}$

Higher IL-6 values in RA patients are well documented and, in the present study, this is also apparent. A cytokinedriven increase in REE has been reported previously in animal studies ${ }^{30}$ and some association has been shown previously in $\mathrm{RA}^{4}$ although not in the context of IL- 6 . However, IL-6 has been implicated in the cachexia of cancer ${ }^{11}$ and some hematological

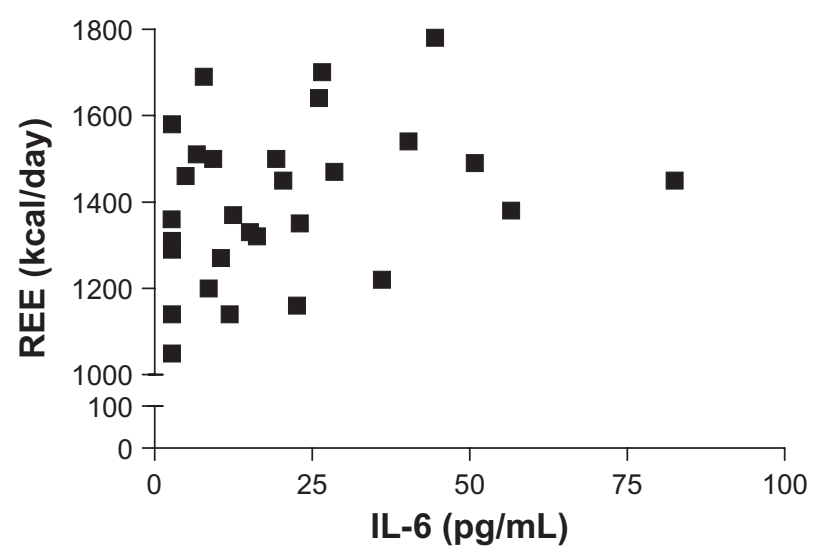

Figure I Relationship between interleukin-6 (IL-6) and resting energy expenditure (REE) in patients with rheumatoid arthritis. The IL-6 and REE were measured and results for both measures were available for 15 of 16 patients at each time point. The Spearman correlation coefficient is $0.32(P=0.08 \mathrm{I})$. 
disorders. ${ }^{31,32}$ The known IL-6 drive of metabolic activity, including an active hepatic acute phase protein response and hemopoetic responses, could reasonably be expected to contribute towards an increased REE and stimulus for protein to be mobilized from skeletal muscle. We did not in fact demonstrate a significant correlation between IL-6 and REE, although the $P$ value (0.08) was close to the level chosen to demonstrate significance. Although a larger sample size may have resulted in a significant correlation, it is still notable that lower REE measurements were not seen when the plasma IL-6 concentration increased, which may indicate that increased IL-6 is one of the factors associated with increasing low REE. The absence of a direct association between a reduction in IL-6 concentration and FFM is not surprising, given that FFM changes over a relatively long period, while IL-6 has a plasma half-life of a few minutes.

Whether some weight loss is inevitable in RA, or whether early aggressive nutritional support can prevent the occurrence of weight loss, requires further study. Evidence from other situations in which cachexia occurs suggests nutritional support may be only partially effective, ${ }^{33}$ although nutritional supplementation with fish oil has been shown to reverse weight loss in cancer cachexia and results in a fall in IL-6 production. ${ }^{34}$ Other therapies, based on drugs to promote anabolism, might also play a future role. However, our data suggest that the most effective measure is likely to be control of inflammatory disease activity.

\section{Disclosure}

The authors disclose no conflicts of interest.

\section{References}

1. Paget J. Nervous mimicry of organic diseases. Lancet. 1873;ii: 727-729.

2. Morley JE, Thomas DR, Wilson MM. Cachexia: pathophysiology and clinical relevance. Am J Clin Nutr. 2006;83:735-743.

3. Muscaritoli M, Anker SD, Argilés J, et al. Consensus definition of sarcopenia, cachexia and pre-cachexia: joint document elaborated by Special Interest Groups (SIG) "cachexia-anorexia in chronic wasting diseases" and "nutrition in geriatrics". Clin Nutr. 2010;29:154-159.

4. Summers GD, Deighton CM, Rennie MJ, Booth AH. Rheumatoid cachexia: a clinical perspective. Rheumatology (Oxford). 2008;47: 1124-1131.

5. Houssiau FA, Devogelaer JP, Van Damme J, de Deuxchaisnes CN, Van Snick J. Interleukin-6 in synovial fluid and serum of patients with rheumatoid arthritis and other inflammatory arthritides. Arthritis Rheum. 1988;31:784-788.

6. Swaak AJ, van Rooyen A, Nieuwenhuis E, Aarden LA. Interleukin-6 (IL-6) in synovial fluid and serum of patients with rheumatic diseases. Scand J Rheumatol. 1988;17:469-474.

7. Giles JT, Ling SM, Ferrucci L, et al. Abnormal body composition phenotypes in older rheumatoid arthritis patients: association with disease characteristics and pharmacotherapies. Arthritis Rheum. 2008;59: 807-815.
8. Metsios GS, Stavropoulos-Kalinoglou A, Koutedakis Y, Kitas GD. Rheumatoid cachexia: causes, significance and possible interventions. Hosp Chronicles. 2006;1:20-26.

9. Greenberg AS, Nordan RP, McIntosh J, Calvo JC, Scow RO, Jablons D. Interleukin 6 reduces lipoprotein lipase activity in adipose tissue of mice in vivo and in 3T3-L1 adipocytes: a possible role for interleukin 6 in cancer cachexia. Cancer Res. 1992;52:4113-4116.

10. Escalante A, Haas RW, del Rincon I. Paradoxical effect of body mass index on survival in rheumatoid arthritis: role of comorbidity and systemic inflammation. Arch Intern Med. 2005;165:1624-1629.

11. Morley JE. Weight loss in older persons: new therapeutic approaches. Curr Pharm Des. 2007;13:3637-3647.

12. Metsios GS, Stavropoulos-Kalinoglou A, Douglas KMJ, et al. Blockade of tumour necrosis factor-alpha in rheumatoid arthritis: effects on components of rheumatoid cachexia. Rheumatology (Oxford). 2007;46: 1824-1827.

13. DeJong $\mathrm{CH}$, Busquets $\mathrm{S}$, Moses $\mathrm{AG}$, et al. Systemic inflammation correlates with increased expression of skeletal muscle ubiquitin but not uncoupling proteins in cancer cachexia. Oncol Rep. 2005;14: 257-263.

14. Arnett FC, Edworthy SM, Bloch DA, et al. The American Rheumatism Association 1987 revised criteria for the classification of rheumatoid arthritis. Arthritis Rheum. 1988;31:315-324.

15. Prevoo MLL, van't Hof MA, Kuper HH, van Leeuwen MA, van de Putte LBA, van Riel PLCM. Modified disease activity scores that include twenty-eight-joint counts. Development and validation in a prospective longitudinal study of patients with rheumatoid arthritis. Arthritis Rheum. 1995;38:44-48.

16. Fuchs HA, Brooks RH, Callahan LF, Pincus T. A simplified twentyeight-joint quantitative articular index in rheumatoid arthritis. Arthritis Rheum. 1989;32:531-537.

17. Pincus T, Summey JA, Soraci SA Jr, Wallston KA, Hummon NP. Assessment of patient satisfaction in activities of daily living using a modified Stanford Health Assessment Questionnaire. Arthritis Rheum. 1983;26:1346-1353.

18. Fries JF, Spitz PW, Young DY. The dimensions of health outcomes: the health assessment questionnaire, disability and pain scales. J Rheumatol. 1982;9:789-793.

19. Durnin JV, Womersley J. Body fat assessed from total body density and its estimation from skinfold thickness: measurements on 481 men and women aged from 16 to 72 years. Br J Nutr. 1974;32:77-97.

20. Weir JB. New methods for calculating metabolic rate with special reference to protein metabolism. Nutrition. 1990;6:213-221.

21. Elkan AC, Engvall IL, Cederholm T, Höfstrom I. Rheumatoid cachexia, central obesity and malnutrition in patients with low-active rheumatoid arthritis: feasibility of anthropometry, Mini Nutritional Assessment and 40. body composition techniques. Eur J Nutr. 2009;48:315-322.

22. Holland B, Welch AA, Unwin ID, et al. McCance and Widdowson's Composition of Foods, 5th ed. Cambridge: The Royal Society of Chemistry and Ministry of Agriculture, Fisheries and Foods; 1991.

23. Snetselaar LG, Chenard CA, Hunsicker LG, Stumbo PJ. Protein calculation from food diaries of adult humans underestimates values determined using a biological marker. J Nutr. 1995;125: 2333-2340.

24. Ma TS, Zuazaga G. Micro-Kjeldahl determination of nitrogen. A new indicator and an improved rapid method. Ind Eng Chem. 1942;14: 280-282.

25. Holt I, Cooper RG, and Hopkins SJ. Relationships between local inflammation, interleukin-6 concentration and the acute phase protein response in arthritis patients. European Journal of Clinical Investigation. 1991;21:479-484.

26. Engvall IL, Elkan AC, Tengstrand B, Cederholm T, Brismar K, Hafstrom I. Cachexia in rheumatoid arthritis is associated with inflammatory activity, 41. physical disability, and low bioavailable insulinlike growth factor. Scand J Rheumatol. 2008;37:321-328.

27. Pierson RN Jr. Body composition in aging: a biological perspective. Curr Opin Clin Nutr Metab Care. 2003;6:15-20. 
28. Book C, Karlsson MK, Akesson K, Jacobsson LT. Early rheumatoid arthritis and body composition. Rheumatology (Oxford). 2009;48: 1128-1132.

29. Clowes GH Jr, George BC, Villee CA Jr, Saravis CA. Muscle proteolysis induced by a circulating peptide in patients with sepsis or trauma. N Engl J Med. 1983;308:545-552.

30. Tocco-Bradley R, Georgieff M, Jones CT, et al. Changes in energy expenditure and fat metabolism in rats infused with interleukin-1. Eur J Clin Invest. 1987; 17:504-510.

31. Beck JT, Hsu SM, Wijdenes J, et al. Brief report: alleviation of systemic manifestations of Castleman's disease by monoclonal anti-interleukin-6 antibody. N Engl J Med. 1994;330:602-605.
32. Emilie D, Wijdenes J, Gisselbrecht C, et al. Administration of an anti-interleukin-6 monoclonal antibody to patients with acquired immunodeficiency syndrome and lymphoma: effect on lymphoma growth and on B clinical symptoms. Blood. 1994;84:2472-2479.

33. Stavropoulos-Kalinoglou A. Metsios GS, Panoulas VF, et al. Underweight and obese states both associate with worse disease activity and physical function in patients with established rheumatoid arthritis. Clin Rheumatol. 2009;28:439-444.

34. Barber MD, Fearon KC, Tisdale MJ, McMillan DC, Ross JA. Effect of a fish oil enriched nutritional supplement on metabolic mediators in patients with pancreatic cancer cachexia. Nutr Cancer. 2001;40: $118-124$.

Journal of Inflammation Research

Dovepress

\section{Publish your work in this journal}

The Journal of Inflammation Research is an international, peer-reviewed open-access journal that welcomes laboratory and clinical findings on the molecular basis, cell biology and pharmacology of inflammation including original research, reviews, symposium reports, hypothesis formation and commentaries on: acute/chronic inflammation; mediators of inflamma- tion; cellular processes; molecular mechanisms; pharmacology and novel anti-inflammatory drugs; clinical conditions involving inflammation. The manuscript management system is completely online and includes a very quick and fair peer-review system. Visit http://www.dovepress.com/ testimonials.php to read real quotes from published authors.

Submit your manuscript here: http://www.dovepress.com/journal-of-inflammation-research-journal 